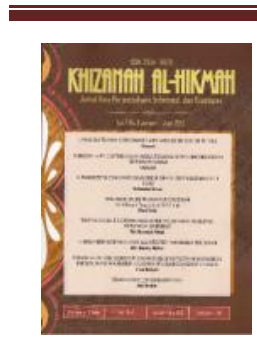

\title{
PEMANFAATAN FITUR Z39.50 PADA SLiMS \\ (Studi Kasus di Perpustakaan Fakultas Adab dan Humaniora UIN Alauddin)
}

\author{
Abdul Syukur*, Taufiq Mathar**, dan Muhammad Azwar***
}

Pengutipan: Syukur, A., Mathar, T., dan Azwar, M. (2016). Pemanfaatan fitur Z39.50 pada SLiMS (studi kasus di Perpustakaan Fakultas Adab dan Humaniora UIN Alauddin). Jurnal Ilmu Perpustakaan, Informasi, dan Kearsipan Khizanah Al-Hikmah, 4(1), 45-56.

\footnotetext{
*Alumni Jurusan Ilmu Perpustakaan UIN Alauddin Makassar (abdsyukur2011@gmail.com)

**Dosen di Jurusan Ilmu Perpustakaan UIN Alauddin Makassar (taufiq.m@uin-alauddin.ac.id) ***Dosen di Jurusan Ilmu Perpustakaan UIN Syarif Hidayatullah Jakarta (muh.azwar@uinjkt.ac.id)
}

\begin{abstract}
ABSTRAK
Z39.50 merupakan protokol standar yang memungkinkan dua sistem komputer terotomasi melakukan proses komunikasi dalam hal sistem temu balik informasi. Pembahasan utama yang diangkat dalam penelitian ini adalah bagaimana pemanfaatan fitur copy cataloging pada aplikasi SLiMS dengan menggunakan fitur protokol Z39.50 di Perpustakaan Fakultas Adab dan Humaniora UIN Alauddin Makassar. Tujuan utama dari penelitian ini adalah untuk mengetahui sejauh mana pemanfaatan protokol Z39.50 serta permasalahan yang dihadapi oleh pengelola perpustakaan dalam melakukan proses salin katalog dari perpustakaan Library of Congress di Amerika Serikat. Data penelitian diperoleh dari staf Perpustakaan Fakultas Adab dan Humaniora. Data yang terkumpul kemudian dianalisis secara kualitatif. Hasil penelitian menunjukkan bahwa pemanfaatan fitur Z39.50 pada SLiMS sudah berjalan dengan baik. Pemanfaatan fitur Z39.50 sangat membantu staf perpustakaan dalam proses penginputan katalog bahan pustaka, khususnya yang berbahasa Inggris, karena menghemat waktu proses penginputan meskipun masih harus melakukan perubahan pada nomor klasifikasi yang mana perpustakaan FAH menggunakan sistem penomoran DDC.
\end{abstract}

Kata Kunci: Protokol Z39.50, Salin katalog, Senayan Library Management System (SLiMS)

\section{ABSTRACT}

Z39.50 is an international standard client-server, application layer communications protocol for searching and retrieving information from a database over a TCP/IP computer network. The current study is focused on how the Z39.50 fiture at SLiMS being used by the FAH library staff. The purposes of the study are divided into two which are (1) to know library staf's perception on the fiture, and (2) to know the difficulties faced by the staf to do copy cataloging from the Library of Congress server. The data was gathered through the library staf experiences and being qualitatively analysed. The study found that the library has been using Z39.50 protocol to copy cataloging English book collections from the Library of Congress server since 2015. Although it makes easier the library to catalog, but some fields need to be edited by the library staf.

Key words: Z39.50 Protocol, Copy cataloging, Senayan Library Management System (SLiMS) 


\section{PENDAHULUAN}

Di era teknologi informasi sekarang ini, mencari informasi bukanlah suatu hal yang sulit. Telah terdapat begitu banyak sumber-sumber informasi yang dapat dimanfaatkan oleh orang-orang untuk memenuhi kebutuhan informasinya, mulai dari sumber tercetak maupun sumber-sumber elektronik. Faktanya, sekarang orang lebih cenderung menggunakan internet ketimbang mediamedia cetak yang ada.

Membludaknya informasi yang ada saat ini, menjadikan setiap individu untuk lebih bijak lagi dalam mencari informasi, khususnya informasi yang tersalurkan melalui media-media elektronik yang ada. Kemampuan manusia untuk menyaring informasi yang akurat juga dibutuhkan, karena ledakan informasi yang begitu cepat menyediakan begitu banyak sumber-sumber informasi sehingga menjadi suatu kendala untuk menentukan sumber-sumber mana saja yang memiliki tingkat akurasi yang tinggi dan informasi mana saja yang sudah kadaluwarsa (Pendit, 2007: 23)

Banyak lembaga-lembaga informasi yang berusaha mengontrol agar informasi mereka tepat sasaran kepada para penggunanya. Salah satu lembaga informasi yang akan dibahas pada tulisan ini yaitu perpustakaan. Kehadiran perpustakaan sebagai lembaga informasi yang menyediakan pelayanan informasi bagi masyarakat berfungsi sebagai penyedia informasi yang tepat dan akurat, dan berusaha seoptimal mungkin mengontrol informasi yang dimilikinya. Tantangan perpustakaan dalam menyediakan informasi di tengah ledakan informasi yang begitu pesat dituntut untuk bisa memberikan informasi dan sumber informasi yang relevan
Dalam menyediakan jasa layanan informasi, perpustakaan juga harus bisa menentukan sumber informasi yang up-todate seiring perkembangan ilmu pengetahuan. Identitas sumber-sumber informasi dari koleksi bahan pustaka yang dimiliki oleh perpustakaan harus jelas demi untuk mengetahui sejauh mana keakuratan informasi bahan pustaka tersebut, sekaligus juga apabila pemustaka ingin melakukan penelusuran lebih lanjut mengenai asal usul dari teori bahan pustaka tersebut untuk memperkaya sumber referensi dari pemustaka. Untuk itu, perpustakaan menyediakan identitas terinci dari setiap bahan pustaka berupa kartu katalog untuk mempermudah penelusuran informasi di perpustakaan.

Perpustakaan bertanggung jawab menyediakan identitas informasi dari setiap bahan pustaka yang dikoleksi oleh perpustakaan tersebut. Dalam proses penginputan katalog bahan pustaka di perpustakaan misalnya, pengelola perpustakaan atau pustakawan di era saat ini dapat menginput dengan melakukan salin katalog (copy cataloging) secara otomatis dari perpustakaan lain yang sudah menyediakan katalog dari bahan pustaka yang tersedia, tanpa harus menginput katalog tersebut. Dalam hal ini, perpustakaan sudah melakukan proses kerjasama dengan perpustakaan lain secara tidak langsung dengan memanfaatkan fitur ini sebagai media pertukaran metadata bahan pustaka.

Dalam melakukan copy cataloging, pustakawan bisa mencari informasi dengan menggunakan satu bahasa protokol yang dikenal dengan istilah Z39.50 sebagai standar komunikasi antara komputer server dan klien, meski pun kedua komputer memiliki perangkat 
keras atau perangkat lunak yang berbeda, sistem pangkalan data yang berbeda, atau sistem logika pencarian yang berbeda (NISO, 4: 2002).

Tulisan ini akan mencoba mengkaji fitur Z39.50 yang telah diterapkan oleh pengelola Perpustakaan Fakultas Adab dan Humaniora (FAH) UIN Alauddin Makassar yang tersedia dalam aplikasi SLiMS atau Senayan Library Management System.

\section{RUMUSAN MASALAH}

Berdasarkan uraian di atas, penelitian ini merumuskan 2 masalah pokok yang akan dicari tahu, yaitu:

a) Bagaimana pemanfaatan fitur Z39.50 pada SLiMS di Perpustakaan Fakultas Adab dan Humaniora UIN Alauddin Makassar?

b) Apa kendala yang dihadapi dalam pemanfaatan fitur Z39.50 pada SLiMS di Perpustakaan Fakultas Adab dan Humaniora UIN Alauddin Makassar?

\section{TUJUAN DAN MANFAAT PENELITIAN}

\section{a. Tujuan Penelitian}

Adapun yang menjadi tujuan penelitian ini yaitu:

1) untuk mengetahui bagaimana pemanfaatan fitur Z39.50 pada SLiMS dalam melakukan proses copy cataloging di Perpustakaan Fakultas Adab Dan Humaniora UIN Alauddin Makassar,

2) untuk mengetahui kendala apa saja yang dihadapi staf perpustakaan Fakultas Adab dan Humaniora dalam menjalankan aplikasi Z39.50 di SLiMS dalam melakukan proses copy cataloging.

\section{b. Manfaat Penelitian}

Penelitian ini diharapkan dapat menjadi tambahan wawasan bagi para praktisi dan akademisi dalam bidang ilmu perpustakaan dan informasi, dan juga bahan referensi dan bahan pertimbangan bagi peneliti-peneliti lainnya yang mungkin tertarik untuk mengkaji subjek yang sama pada penelian ini.

\section{TINJAUAN TEORETIS}

\section{a. Otomasi Perpustakaan}

Sistem otomasi merupakan salah satu bentuk penerapan teknologi informasi di perpustakaan dalam upaya melaksanakan berbagai pelayanan dan pengelolaan perpustakaan. Penerapan system otomasi dilatarbelakangi alasan bahwa dengan mengotomasikan perpustakaan dapat memberikan manfaat optimal bagi pengelolaan dan penggunaan perpustakaan (Azwar, 2015).

Otomasi perpustakaan mutlak diperlukan oleh setiap perpustakaan untuk memaksimalkan tujuan, fungsi, dan tugasnya sebagai lembaga penyedia informasi di era digital. Dengan menerapkan otomasi, penelusuran bahan pustaka juga bisa lebih cepat dan akurat melalui OPAC (Online Public Access Catalog).

Telah banyak perpustakaan yang menerapkan sistem otomasi perpustakaan, baik itu jenis perpustakaan kecil ataupun perpustakaan yang memiliki koleksi yang banyak. Tentu saja banyak manfaat yang dirasakan jika sebuah perpustakaan telah menerapak 
sistem otomasi perpustakaan. Manfaat yang dimaksud adalah di antaranya (1) mengefisienkan dan mempermudah pekerjaan dalam perpustakaan, memberkan layanan yang lebih baik kepada pengguna perpustakaan, (3) meningkatkan citra perpustakaan, (4) pengembangan infrastruktur nasional, regional, dan global (Supriyanto, 2008: 37).

Perpustakaan yang telah terotomasi biasanya lebih mengikuti perkembangan yang terjadi dalam dunia kepustakawanan. Namun demikian, tidak sedikit juga kita masih jumpai beberapa perpustakaan-perpustakaan yang masih menerapkan cara-cara konvensional dalam pengelolaan perpustakaannya.

\section{b. Salin Katalog (Copy Cataloging)}

Menurut Himayah (2013) katalog merupakan daftar dari koleksi perpustakaan atau beberapa perpustakaan yang disusun secara sistematis, sehingga memungkinkan pengguna perpustakaan dapat mengetahui dengan mudah koleksi apa yang dimiliki oleh perpustakaan dan di mana koleksi tersebut dapat ditemukan.

Sebelum terjadi perkembangan pesat dalam bidang teknologi informasi dan komunikasi, perpustakaan masih menggunakan katalog kartu dalam mengelola koleksi perpustakaan. Namun seiring dengan perkembangan zaman ini, kartu katalog perlahan-lahan mulai diotomasikan.

Kartu katalog di perpustakaan mempunyai fungsi yang sangat penting di perpustakaan, dengan kartu katalog, pemustaka bisa menelusur informasi bahan pustaka di perpustakaan dengan mudah. Penelusuran bahan pustaka di perpustakaan bisa ditelusur dengan menggunakan tiga metode penelusuran, yakni judul, penulis, atau subyek. Data yang terdapat pada kartu katalog atau pun yang tertera di layar komputer sebagai katalog elektronik berisi tentang data atau identitas bahan pustaka yang tersimpan di perpustakaan sebagai panduan lokasi di rak mana bahan pustaka tersebut disimpan.

Seorang pustakawan yang melakukan proses pengatalogan bahan pustaka disebut dengan kataloger (cataloger). Kataloger harus memiliki pengetahuan di bidang katalogisasi yang diperolehnya melalui jalur pendidikan formal dalam bidang ilmu perpustakaan atau pun dari pelatihan-pelatihan kepustakawanan.

Di era saat ini, sebagaimana yang telah diuraikan sebelumnya bahwa telah banyak perpustakaan yang telah beralih dari katalog kartu menjadi katalog daring (online) yang tidak lain tujuannya ialah untuk memperluas jangkauannya kepada para pemustaka. Ketika banyak perpustakaan telah memiliki katalog daring, maka proses penyalinan katalog dari satu katalog perpustakaan ke katalog perpustakaan yang lainnya telah menjadi tren saat ini. Tentu saja hal ini memberikan manfaat seperti yang telah diuraikan sebelumnya.

Copy cataloging atau yang dalam bahasa Indonesianya ialah salin katalog adalah proses pengambilan informasi katalog yang sudah dibuat sebelumnya dan diterapkan untuk penggunaan lokal (Kao, 2001: 97). Jadi, penyediaan katalog di perpustakaan dengan menggunakan katalog yang sudah dikatalog sebelumnya dari perpustakaan atau organisasi perpustakaan lain. Selain menghemat waktu, copy cataloging juga bisa menghemat biaya dan kinerja staf 
perpustakaan didasarkan dengan kecepatan kerja tapi dengan kualitas yang bagus.

Proses copy cataloging sudah menjadi praktik yang umum diterapkan di perpustakaan di seluruh dunia. Copy cataloging sebisa mungkin dilakukan di perpustakaan sebagai efisiensi pelayanan perpustakaan, yaitu untuk memudahkan input data bibliografi bahan pustaka ke dalam pangkalan data sebuah perpustakaan. Input data bibliografi bahan pustaka ke dalam suatu pangkalan data bisa memakan waktu yang cukup lama dan harus teliti. Input yang dimaksud adalah memasukkan judul buku, nama pengarang, kota terbit, tahun terbit, kolasi, deskripsi bibliografi, nomor kelas dan abstrak. Proses tersebut menyita waktu staf perpustakaan dalam penginputan data bibliografi.

Di dalam aplikasi sistem otomasi seperti SLiMS, copy cataloguing bisa dilakukan dengan menggunakan layanan Peer to Peer (P2P Service) dan protocol Z39.50. Layanan P2P artinya dapat copy cataloguing dari sesama pengguna aplikasi (misalnya sesama SLiMS). Protokol Z39.50 merupakan protokol client server berstandar internasional (ISO Z3950) untuk penelusuran dan temu balik informasi antar komputer yang terhubung jaringan internet (Azwar, 2013).

\section{c. Protokol Z39.50}

Salah satu faktor penunjang perpustakaan melakukan proses pengkatalogan adalah adanya protokol Z39.50. Z39.50 merupakan protokol komunikasi yang memungkinkan perpustakaan untuk menerima data bibliografi bahan pustaka dari sebuah sistem yang sudah terotomasi dengan
MARC dan digunakan di sistem perpustakaan lokal (Kochtanek, 2002: 62). Data bibliografi tersebut disalin dari katalog induk ke dalam pangkalan data perpustakaan lokal yang mempunyai akses terhadap katalog induk melalui protokol Z39.50 untuk selanjutnya ditampilkan di OPAC sebagai identitas bahan pustaka perpustakaan tersebut.

Z39.50 merupakan protokol standar yang memungkinkan dua sistem komputer terotomasi melakukan proses komunikasi dalam hal sistem temu balik informasi (NISO, 3: 2002). Z39.50 merupakan protokol yang sudah cukup lama dikenal di dunia kepustakaan, di mana protokol ini merupakan sebuah titik balik dari dua dekade perdebatan dan pemikiran tentang bagaimana sistem temu balik informasi bisa distandarkan, dimodifikasi, dan diterapakan pada sistem penyebaran informasi seperti perpustakaan.

Z39.50 merupakan sebuah protokol yang didasarkan pada pelayanan antara client dan server dalam melakukan penelusuran informasi (information retrieval). Protokol $\mathrm{Z} 39.50$ berisi tentang prosedur dan format untuk client untuk mencari informasi yang disediakan oleh server, lalu rekaman data tersebut diterima oleh client, dan ditampilkan pada identitas suatu informasi yang diadaptasikan dengan format tertentu berdasarkan ketentuan yang ditetapkan perpustakaan client.

\section{METODOLOGI PENELITIAN}

\section{a. Jenis Penelitian}

Penelitian ini merpuakan penelitian deskriptif yaitu suatu metode dalam meneliti status sekelompok manusia, 
suatu kondisi, suatu sistem pemikiran, ataupun suatu kelas peristiwa pada masa sekarang (Nasir, 2005: 54) Tujuan dari penelitian deskriptif ini adalah untuk membuat deskriptif, gambaran atau suatu lukisan secara sistematis, faktual dan akurat mengenai fakta-fakta, sifat-sifat hubungan antar fenomena yang diselidiki.

Metode yang digunakan dalam penelitian ini dalah metode penelitian kualitatif yaitu metode penelitian yang digunakan untuk meneliti kondisi objek yang alamiah, dimana peneliti bertindak sebagai instrumen kunci, teknik pengumpulan data dilakukan secara trianggulasi (gabungan), analisis data bersifat induktif, dan penelitian kualitatif lebih menekankan makna dari pada generalisasi (Sugiono, 2013: 1).

\section{b. Sumber Data}

Data penelitian ini bersumber dari para informan penelitian (staf perpustakaan FAH UIN Alauddin) dan juga aplikasi SLiMS itu sendiri.

\section{c. Teknik Pengumpulan Data}

Pengumpulan data dilakukan dengan cara wawancara, observasi langsung, dan juga dokumen-dokumen lainnya yang terkait dengan fitur Z39.50.

\section{d. Instrumen Penelitian}

Pedoman wawancara yang dibangun berdasarkan teori yang relevan menjadi instrumen utama dalam penelitian ini. Selain itu tape recorder, kamera digital, screenshot, juga menjadi instrumen pendukung dalam mengumpulkan datadata penelitian.

\section{e. Teknik Analisis Data}

Analisis data dengan menggunakan teknik analisis deskriptif kualitatif, yaitu dengan menunjukkan satu persatu hasil penelitian lalu setelah itu data-data tersebut ditelaah dan dikritisi berdasarkan teori yang berkembang. Reduksi data juga menjadi penting untuk diketahui untuk menghindari meluasnya cakupan penelitian ini.

\section{HASIL PENELITIAN DAN PEMBAHASAN}

\section{a. Pemanfaatan Fitur Protokol Z39.50}

Perpustakaan Fakultas Adab dan Humaniora (FAH) sudah berdiri sejak Fakultas ini juga didirikan pada tahun 1967. Sebagaimana sama dengan perpustakaan-perpustakaan fakultas lainnya yang ada di lingkup UIN Alauddin Makassar, perpustakaan ini bertujuan untuk mendukung UPT Perpustakaan UIN Alauddin, selaku induk perpustakaan, dalam menyediakan sarana belajar bagi para mahasiswa.

\section{Gagasan untuk mengotomasi} perpustakaan ini dirancang pada akhir tahun 2014 oleh pimpinan perpustakaan, yaitu Hildawati Almah, S.Ag., S.S., M.A, yang juga merupakan dosen di Jurusan Ilmu Perpustakaan UIN Alauddin Makassar. Perkembangannya sejak saat itu hingga saat ini sangat signifikan. Layanan peminjaman dan pengembalian buka telah dilakukan secara otomasi dengan menerapakan aplikasi SLiMS (Senayan Library Management System).

Mengenai kegiatan katalogisasi bahan pustaka, saat ini terdapat 5 orang mahasiswa magang yang melakukan kegiatan tersebut dengan mendapat bimbingan dari staf perpustakaan. Koleksi 
perpustakaan FAH memiliki variatif bahasa; bahasa Inggris, Arab, dan bahasa Indonesia. Untuk koleksi yang berbahasa Inggris, proses katalogisasi dilakukan dengan cara salin katalog dari Perpustakaan Kongress Amerika Serikat. Hampir sebagian besar buku dalam bahasa Inggris tersebut memilki katalog di perpustakaan tersebut, sehingga proses katalogisasi lebih mudah lagi.

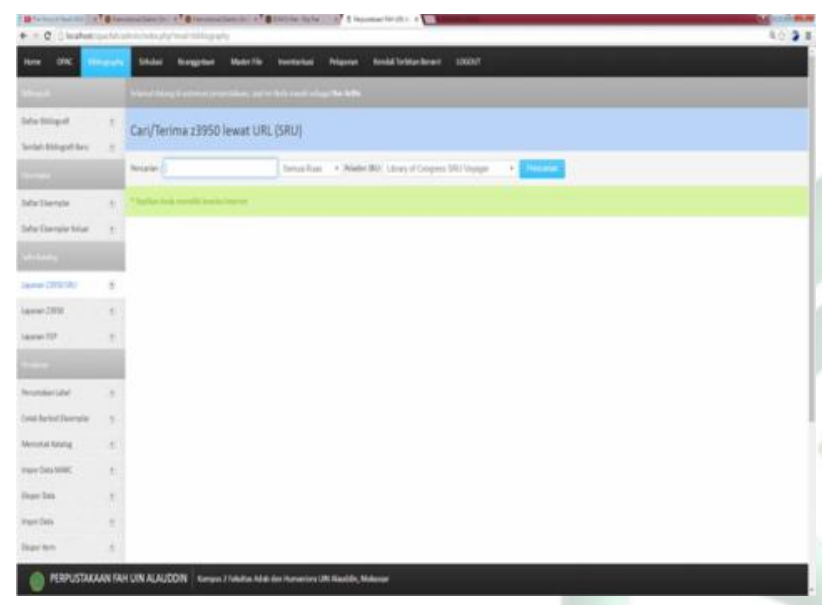

Gambar 1.

Fitur Z39.50 pada SLiMS Perpustakaan FAH

Fungsi utama dalam pemanfaatan fitur protokol Z39.50 pada aplikasi SLiMS adalah untuk memudahkan katalogisasi bahan pustaka. Dalam fitur bibliografi, staf perpustakaan melakukan proses penginputan data biliografi dari bahan pustaka dengan mengisi kolom identitas bahan pustaka seperti judul buku, pengarang, jilid, penerbit, tahun terbit, nomor kelas, abstrak, subyek dan lainlain. Hal ini dimaksudkan untuk memudahkan sistem temu balik informasi di perpustakaan.

Dengan adanya fitur Z39.50, staf perpustakaan sangat terbantu karena tidak perlu lagi melakukan proses penginputan katalog pada fitur bibliografi di aplikasi SLiMS. Fitur ini memungkinkan staf perpustakaan untuk melakukan copy cataloging atau salin katalog bahan pustaka dari perpustakaan lain yang sudah melakukan input katalog bahan pustaka yang sama.

Perbandingan antara penginputan katalog secara langsung di fitur bibliografi pada aplikasi SLiMS dengan melakukan copy cataloging melalui fitur protokol Z39.50 pada aplikasi yang sama ternyata mempunyai perbedaan yang sangat berarti oleh staf perpustakaan. Perbedaan itu terletak pada efisiensi waktu dan kejelasan informasi. Penginputan katalog secara langsung pada SLiMS memakan waktu sekitar lima sampai sepuluh menit setiap buku, tergantung dari kemampuan kataloger.

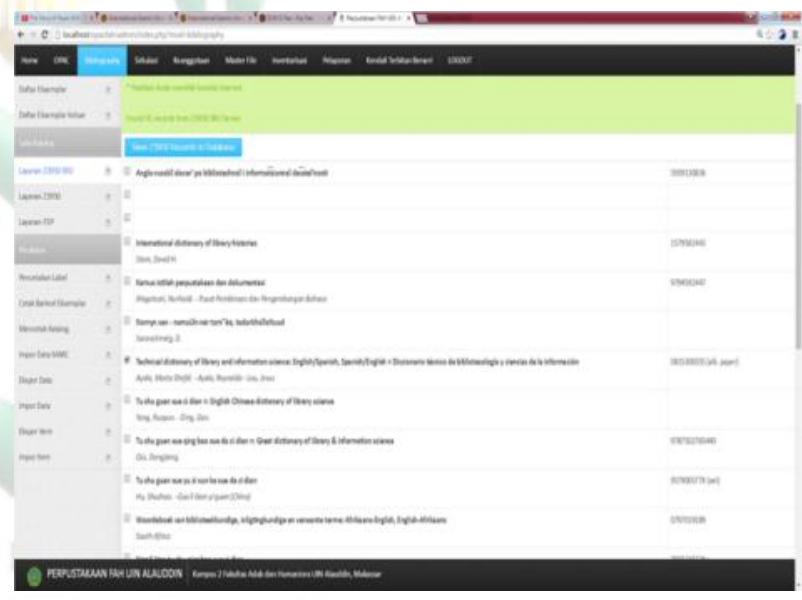

Gambar 2.

Contoh sebuah koleksi buku bahasa Inggris yang di copy dari server Library of Congress

Terkadang bahan pustaka yang dikatalog memiliki informasi yang tidak lengkap, seperti tidak tercantum kota terbitnya, nomor kelas yang tidak akurat, subyek yang tidak sesuai. Hal tersebut menjadi faktor penghambat dalam melakukan proses input katalog secara manual. Dalam waktu selama itu, terkadang juga jaringan internet sebagai 
syarat utama penggunaan aplikasi SLiMS tiba-tiba terputus.

Aplikasi SLiMS tidak dilengkapi dengan auto-save atau menyimpan secara otomatis jika penggunaan SLiMS terhenti secara tiba-tiba seperti jaringan internet terputus, listrik padam, atau kesalahan pada komputer. Dan apabila proses penginputan bahan pustaka terhenti secara tiba-tiba, maka data bibliografi bahan pustaka tersebut tidak tersimpan dan harus diulangi kembali dari awal.

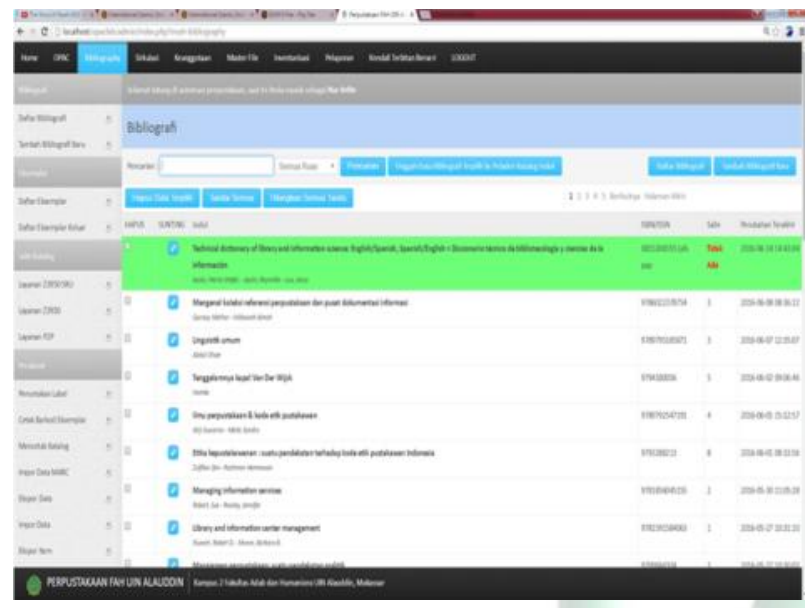

Gambar 3.

Proses copy cataloging berhasil, data buku telah masuk ke dalam bibliografi

Adanya fitur Z39.50 di SLiMS bisa mereduksi risiko-risiko di atas. Dalam melakukan proses copy cataloging dengan memanfaatkan fitur protokol Z39.50 mampu mempersingkat durasi penginputan bahan pustaka. Staf perpustakaan hanya membutuhkan beberapa detik saja dalam memasukkan data bibliografi bahan pustaka tersebut ke dalam pangkalan data SLiMS di Perpustakaan FAH.

"SLiMS sangat membantu kami dalam melakukan proses katalogisasi bahan pustaka, khususnya yang berbahasa Inggris, karena hampir sebagain besar buku-buku tersebut dapat kami jumpai di Perpustakaan Kongres Amerika" (hasil wawancara dengan salah seorang informan 16 Oktober 2015).

Dalam memanfaatkan fitur protokol Z39.50, staf perpustakaan memasukkan nomor ISBN atau nomor ISSN dari bahan pustaka yang bersangkutan pada kolom pencari atau search. Staf perpustakaan juga bisa memasukkan kata kunci berupa nama pengarang atau bisa juga dengan memasukkan nama judul atau judul seri dari bahan pustaka yang ingin dikatalog. SLiMS yang terdapat di Fakultas Adab dan Humaniora terhubung ke Library of Congress Voyager sebagai peladen, karena koleksi katalognya lebih lengkap dan hampir semua sumber informasi dari seluruh dunia terhimpun di katalog Library of Congress.

Setelah staf perpustakaan memasukkan kata kunci pada kolom pencarian (ISBN/ISSN, nama pengarang, atau judul bahan pustaka), staf perpustakaan lalu menekan tombol enter pada papan kunci komputer. Setelah itu, akan muncul daftar buku yang cocok dengan kata kunci yang dimasukkan di kolom pencarian.

Apabila kata kunci yang dimasukkan lebih spesifik seperti penggunaan nomor ISBN sebagai kata kunci, maka hasil pencarian yang sesuai dengan kata kunci yang dimasukkan hanya akan menampilkan satu hasil pencarian. Karena setiap bahan pustaka seperti buku, majalah, jurnal dan lain sebagainya memiliki kode unik masing-masing yang dikenal sebagai ISBN (International Standard Book Number) atau ISSN (Intenrational Standard Serial Number) yang tidak memiliki nomor yang sama dengan bahan pustaka yang lain. 
Setelah hasil pencarian muncul, maka bahan pustaka yang ingin dimasukkan ke dalam katalog perpustakaan dicentang, lalu klik tombol Save Z3950 Records to database. Maka data bibliografi bahan pustaka tersebut sudah tersimpan di pangkalan data SLiMS Fakultas Adab dan Humaniora.

Terdapat sedikit perbedaan format penulisan katalog yang diterapkan oleh Perpustakaan Fakultas Adab dan Humaniora UIN Alauddin Makassar. Perbedaan tersebut hanya terletak pada penggunaan sistem klasifikasi. Sistem klasifikasi yang diterapkan oleh Library of Congress adalah LCC atau Library of Congress Classification, sedangkan Perpustakaan Fakultas Adab dan Humaniora UIN Alauddin Makassar menggunakan Dewey Decimal Classification (DDC) atau skema klasifikasi persepuluhan Dewey. Jadi setiap data bibliografi yang disalin dari Perpustakaan Library of Congress melalui proses copy cataloging harus disunting terlebih dahulu oleh staf perpustakaan dan mengganti nomor kelas yang sesuai dengan DDC.

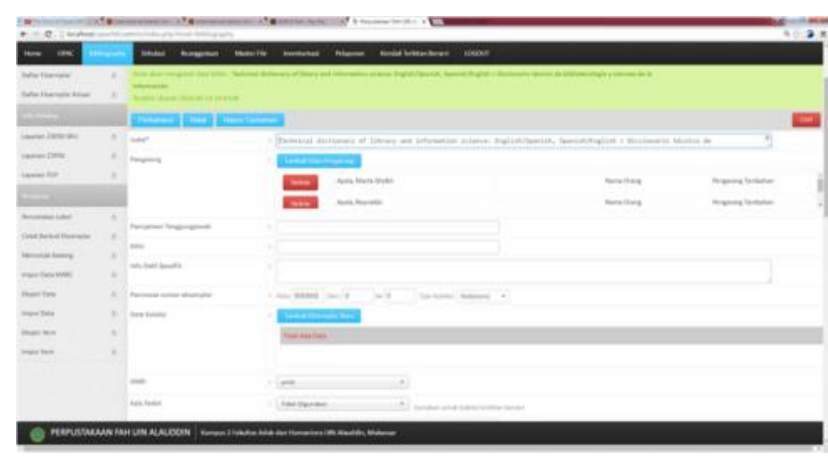

Gambar 4.

Penyuntingan bibliografi dari server Library of Congress

Dalam proses penyuntingan bibliografi bahan pustaka yang diperoleh melalui hasi copy cataloging, staf perpustakaan Fakultas Adab dan
Humaniora memanfaatkan bibliografi induk dari OCLC (Online Computer Library Center) melalui laman http:/ / classify.oclc.org.

Selanjutnya, seorang informan menyatakan bahwa "Kami biasanya menggunakan OCLC Classify, untuk membantu melihat nomor kelas dari bahan pustaka yang kami input dengan menggunakan sistem DDC, karena sebagaimana yang diketahui bahwa Perpustakaan FAH menggunakan sistem DDC untuk penomoran klas-nya, sementara data no klas yang kami peroleh dari Perpustakaan Kongress Amerika menggunakan sistem LCC (wawancara 16 Oktober 2015).

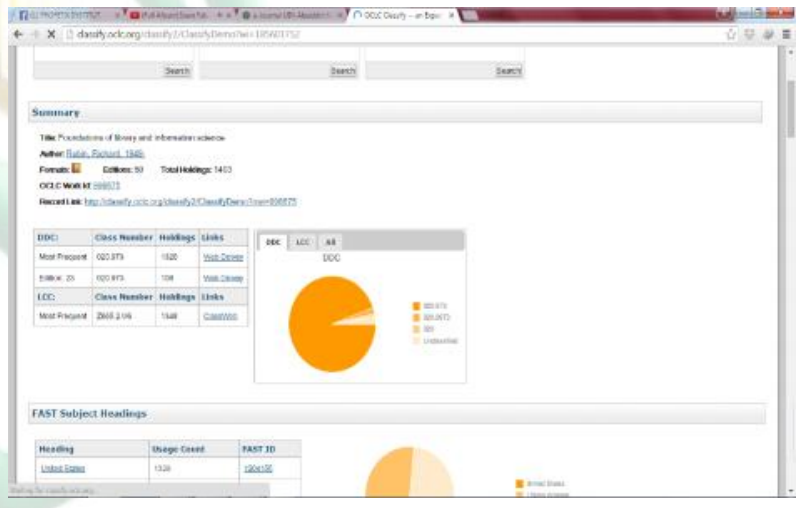

Gambar 5.

Website http://classify.oclc.org

b. Kendala-kendala dari Pemanfaatan Fitur Z39.50

Meski pemanfaatan fitur protokol Z39.50 pada SLiMS banyak membantu staf perpustakaan dalam melakukan proses katalog dengan cepat dan efisien, ada beberapa kendala yang dihadapi oleh staf perpustakaan dalam mengoperasikan fitur protokol Z39.50 pada SLiMS. Perlu diketahui bahwa tidak semua koleksi yang ada di Perpustakaan FAH, cantuman bibliografinya juga tersedia di Library of 
Congress. Tentu saja, koleksi-koleksi tersebut, tidak dapat dilakukan copy cataloging.

Namun demikian, terdapat juga beberapa buku berbahasa Indonesia yang terdaftar di katalog Library of Congress, yakni buku-buku yang memiliki reputasi nasional dan internasional dan masuk dalam kategori best seller seperti novel Laskar Pelangi, Sang Pemimpi, Edensor, Negeri Lima Menara dan beberapa lainnya.

Proses copy cataloging secara online seperti ini tentu saja bergantung pada jaringan internet (berbeda dengan proses copy-cataloging peer-to-peer, atau melalui flashdisk). Jaringan internet yang sering terputus secara tiba-tiba juga meruapakan suatu kendala. Koneksi internet adalah syarat yang paling utama dalam pemanfaatan fitur protokol Z39.50. karena interoperabilitas temu balik informasi antara komputer client dan komuter server dengan perantara bahasa protokol Z39.50 terhubung melalui koneksi internet.

Seorang informan menyebutkan bahwa "terkadang tiba-tiba aliran listri putus, sehingga mematikan semua peralatan komputer dan jaringan internet nirkabelnya, jadi kami harus menunggu sampai listriknya aktif kembali" (wawancara 26 Oktober 2015). Meskipun demikian, kendala-kendala seperti ini menurut hemat penulis adalah hal yang wajar dijumpai diberbagai macam lembaga saat ini.

Kendala-kendala di atas bukanlah kendala besar, akan tetapi dapat menghambat proses pelayanan di perpustakaan dan perlu juga mendapat perhatian. Bukan hanya proses copy cataloging, tetapi pelayanan lain juga akan terganggu seperti layanan OPAC, sirkulasi, dan keanggotaan. Apabila kendala tersebut terjadi di Perpustakaan Fakultas Adab dan Humaniora, maka proses pelayanan akan diganti menjadi pelayanan manual yaitu dilakukan dengan pencatatan pada buku atau worksheet.

Kendala utama dalam proses salin katalog ini yaitu, sebagaimana yang telah diuraikan juga sebelumnya, cantuman bibliografi yang masuk ke dalam database SLiMS FAH perlu disunting di beberapa bagian. Contohnya, no klasifikasi dan subjek. Untuk no klasifikasi, kataloger mesti menentukan lagi no klasifikasi bahan pustaka tersebut. Demikian pula dengan subjek koleksi tersebut, kataloger juga harus menentukan tajuk subjek bahan pustaka yang telah tercantum dalam database. Menarik untuk diketahui bahwa semua koleksi yang telah tersalin ke dalam database SLiMS Perpustakaan FAH, meskipun memiliki judul yang berbeda-beda namun semuanya memilki subjek yang sama yaitu "Perpustakaan". Jadi jelas di sini perlu mendapat perhatian khusus oleh para penyalin, bahwa mereka harus mengubah dan menentukan kembali subjek bahan pustaka yang baru saja di salin dari Library of Congress.

\section{KESIMPULAN DAN SARAN}

\section{a. Kesimpulan}

Dari pembahasan singkat di atas, penelitian ini dapat menyimpulkan, yaitu:

1) Pemanfaatan fitur protokol $Z 39.50$ pada SLiMS di Perpustakaan Fakultas Adab dan Humaniora UIN Alauddin Makassar memberikan manfaat dan pengetahuan yang besar bagi pengelola perpustakaan. Adanya fitur protokol Z39.50 pada SLiMS 
membantu staf perpustakaan dalam melakukan pengatalogan dengan cepat dan efisien jika dibandingkan dengan pengatalogan secara manual pada kolom bibliografi di aplikasi SLiMS. Dengan demikian, staf perpustakaan bisa menghemat waktu proses katalogisasi bahan pustaka.

2) Ada beberapa kendala yang dihadapi oleh staf perpustakaan dalam melakukan proses copy cataloging bahan pustaka pada SLiMS, yakni koneksi internet yang menjadi syarat utama dalam pemanfaatan protokol Z39.50 terkadang terputus dan menghambat proses tersebut. Kendala lainnya yaitu pengelola perpustakaan mesti menentukan no klasifikasi dan subjek bahan pustaka.

\section{b. Saran}

Beberapa yang dapat kami sarankan pada penelitian ini yaitu:

1. Pemanfaatan fitur Z39.50 perlu terus diterapkan meskipun masih menyisakan ketidaklengkapan cantuman bibliografi dari server lainnya.

2. Aplikasi SLiMS perlu menambahkan server-server katalog lainnya lagi dalam proses salin katalog.

3. Perpustakaan FAH UIN Alauddin dapat membagi pengalamannya dalam pemanfaatan fitur tersebut kepada perpustakaan-perpustakaan lainnya yang juga menggunakan aplikasi SLiMS.

\section{DAFTAR PUSTAKA}

Abdul Rahman Saleh. 2010. Membangun Perpustakaan Digital. Jakarta: Sagung Seto.
Andi Ibrahim. 2014. Pengantar Ilmu Perpustakaan. Makassar: Gunadarma Ilmu.

Azwar, M. (2013). Membangun Sistem Otomasi Perpustakaan dengan Senayan Library Management System (SLiMS). Jurnal Ilmu Perpustakaan $\mathcal{E}$ Informasi KHIZANAH AL-HIKMAH, 1(1), 1933. Diambil dari http://journal.uinalauddin.ac.id/index.php/khizana h-al-hikmah/article/view/23

Azwar, M. (2015). Penerapan Sistem Otomasi di Perpustakaan Fakultas Adab dan Humaniora UIN Alauddin Makassar. Al-Kuttab : Jurnal Perpustakaan Dan Informasi, 2(1), 45-67. Retrieved from http:/ / ejournal.perpustakaanstainpsp.net/i ndex.php/alkuttab/article/view/5 1

Departemen Pendidikan Nasional. 2008. Kamus Besar Bahasa Indonesia. Jakarta: Balai Pustaka.

Hammer, Sebastian. 1996. Z39.50 and the World Wide Web. UDT Occasional Paper, 1.

Himayah. 2013. Katalogisasi II : Deskripsi Bibiliografi Bahan Pustaka Multimedia. Makassar: Alauddin Press.

International Standard Organization. 2002. Z39.50: A Primer on the Protocol. 3.

Kao, Mary L. 2001. Cataloging and Classification For Library Technicians. New York: Haworth Press.

Kochtanek, Thomas. R. 2002. Library Information Systems: From Library Automation to Distributed Information Access Solution. Connecticut: Libraries Unlimited.

Lasa HS. 2008. Manajemen Perpustakaan. Yogyakarta: Gramedia. 
Lexy J. Moeloeng. 2000. Metodologi Penelitian Kualitatif. Bandung: Remaja Rosdakarya.

Lexy J. Moelong. 2007. Metode Penelitian Kualitatif. Bandung: Rosdakarya Remaja.

Lynch, Clifford. A. 1997. The Z39.50 Information Retrieval Standard. DLib Magazine, 4.

Mestika Zed. 2008. Metode Penelitian Kepustakaan. Jakarta: Yayasan Obor Indonesia.

Moh. Nasir. 2005. Metode Penelitian. Bogor: Ghalia Indonesia.

Muin, M. A. (2014). Information literacy skills: strategi penelusuran informasi online. Makassar: Alauddin University.

Pawit M. Yusup. 2010. Teori \& Praktik Penelusuran Informasi: Information Retrieval. Jakarta: Kencana.

Putu Laxman Pendit. 2007. Perpustakaan Digital: Perspektif Perpustakaan Prguruan Tinggi Indonesia. Jakarta: Sagung Seto.

Republik Indonesia. 2009. Undang Undang RI Nomor 43 Tahun 2007 Tentang Perpustakaan Tahun 2009. Jakarta: Tamita Utama.

Schmidt, Eric. 2014. The New Digital Age: Cakrawala Baru Negara, Bisnis, dan Hidup Kita. Jakarta: Gramedia.

Sitti Husaebah Pattah Habsy. 2013. Organisasi Informasi di Perpustakaan dan Pusat Dokumentasi dan Informasi: Sebuah Pengantar. Makassar: Alauddin Press.

Sugiyono. 2008. Metode Penelitian Kuantitatif, Kualitatif dan R\&D. Bandung: Alfabeta.

Suharismi Arikunto. 1992. Prosedur Penelitian. Jakarta: Rineka Cipta.

Sumardi Suryabrata. 2009. Metodologi

Penelitian. Jakarta: Rajawali Press.
Sutarno NS. 2006. Manajemen Perpustakaan. Jakarta: Sagung Seto. Suwarno. 2014. Perpustakaan Dan Buku: Wacana Penulisan Dan Penerbitan. Yogyakarta: Ar-Ruzz Media.

Testiani Makmur. 2015. Budaya Kerja Pustakawan di Era Globalisasi. Yogyakarta: Graha Ilmu.

Tim Pustaka Phoenix. 2013. Kamus Besar Bahasa Indonesia. Jakarta: Pustaka Phoenix.

Turner, Fay. 1997. An Overview of the Z39.50 Information Retrieval Standard. UDT Occasional Paper, 1. Universitas Islam Negeri Alauddin Makassar. 2014. Pedoman Karya Tulis Ilmiah: Makalah, Skripsi, Tesis, Disertasi dan Laporan Penelitian. Makassar: Alauddin Press.

Wahyu Supriyanto. 2008. Teknologi Informasi Perpustakaan: Strategi Perencanaan Perpustakaan Digital. Yogyakarta: Kanisius.

Widyawan, Rosa. 2014. Agar Informasi Menjadi Lebih Seksi: Pengantar Pelayanan Kemas Ulang Informasi. Jakarta: Media Kampus Indonesia.

Yaya Suhendar. 2010. Pedoman Katalogisasi. Jakarta: Kencana. 